DOI: http://doi.org/10.21698/simi.2017.0016

\title{
ASSESSMENT OF THE ENVIRONMENTAL ASPECTS IN A CITY AREA AFFECTED BY HISTORICAL POLLUTION
}

\author{
Bogdan Stanescu, Lidia Kim, Carol Lehr, Elena Stanescu
}

National Research and Development Institute for Industrial Ecology ECOIND Bucharest, 71-73 Drumul Podu Dambovitei, 060652, Bucharest, Romania, evmt@incdecoind.ro

\begin{abstract}
The paper presents the results obtained by performing specific activities aimed to assess the quality of the soil and water components (surface and groundwater) in Copsa Mica, a small town from Romania, well known for the historical pollution recorded over several decades. It is known that the contamination was induced by the industrial activities carried out in the area, which is caused by sulfur dioxide air emissions and atmospheric particulate matters containing heavy metals, mainly cadmium, lead and zinc. The pollution of the city and the neighboring areas was mainly due to activities of two companies: SC Sometra SA (with a non-ferrous metallurgy profile, which before 1990 was considered the largest unit in the country) and SC Carbosin SA (with a chemical profile until its closing, in 1993). The assessment of the quality level of the environmental factors was carried out in 2016 through specific activities for soil and water quality investigation - sampling and physico-chemical analysis in R\&D Institute for Industrial Ecology ECOIND laboratories, in order to highlight relevant elements of environmental quality of the above mentioned year, within a pre-established experimental field and targeting the limited area of the Copsa Mica city. As an important aspect, it is worth mentioning that the footprint of the pollution sources is still present in the area, even long after their activity has ceased. It is estimated that a soil and water monitoring could establish a dynamics of the quality parameters in the Copsa Mica area during the subsequent periods.
\end{abstract}

Keywords: assessment, environment quality, heavy metals, pollution

\section{Introduction}

Industrial polllution has been and continues to be a major factor causing the degradation of the environment (Muntean 2010). Copsa Mica city is located in the North-West of Sibiu County, at the confluence of the Tirnava Mare river with Visa. Crossed by DN14, the city is located $43 \mathrm{~km}$ from the county seat, $12 \mathrm{~km}$ from Medias and $33 \mathrm{~km}$ from Blaj on DN 14B (Szanto 2011). The city is bordered by Bazna commune and resort, to the North-East by Tirnava commune and Medias municipality, by the commune of Valea-Viilor to the East, by the Axente Sever commune to the South and the Micasasa commune to the West. The city is located in the depression corridor of the Tarnava Mare River, surrounded by hills (Figure 1). The city of Copsa Mica is well known for the historical pollution induced by the industrial activities carried out in the area (over 60 years) which is attributed to 


\section{INTERNATIONAL SYMPOSIUM "THE ENVIRONMENT AND THE INDUSTRY", SIMI 2017, PROCEEDINGS BOOK}

gaseous emissions containing sulphur dioxide and atmospheric particulates containing heavy metals, mainly $\mathrm{Cd}, \mathrm{Pb}$ and $\mathrm{Zn}$. (Lacatusu 2010).

The ecological importance of the presence of heavy metals in urban soils is closely related to human health due to their high ecological transference reported as an indicator of urban environmental quality (Stanescu 2016). Recent studies underline the importance of the correlation between the state of terrestrial ecosystems and groundwater, considering that one of the basic principles in this field is based on groundwater protection policy against pollution and deterioration, as included in EU Water Framework Directive 2000/60 EC and Directive 2006/118/EC (Scradeanu 2016).

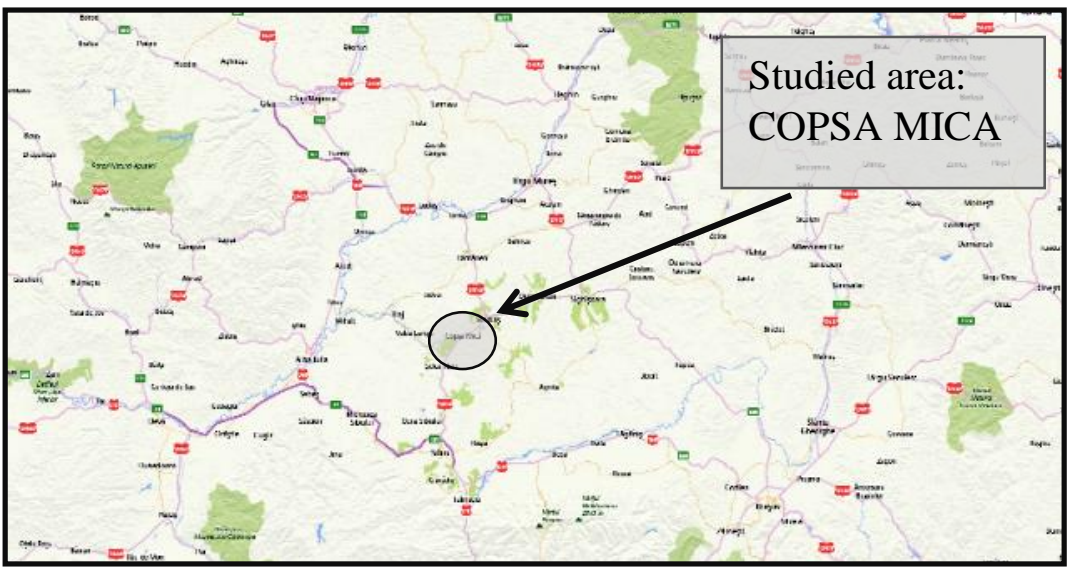

Figure 1. Localization of the studied area - Copsa Mica City

The pollution of Copsa Mica and neighboring areas was mainly due to two companies: SC Sometra SA with a non-ferrous metallurgy profile, which before 1990 was considered the largest unit of this type in the country and, until 1993, SC Carbosin $\mathrm{SA}$, with a chemical profile.

Important issues were revealed by field visits in 2016 that highlighted the following: - the current pollution sources are limited to heavy road traffic on DN14, a rehabilitated road in recent years, which has traffic values that can reach 30000 vehicles / 24 hours and sporadic activity and much diminished at SC SOMETRA SA, whose activity is regulated from the point of view of environmental protection;

- the only source of drinking water in the city is the underground water, provided by a public wells network distributed throughout the city. The water from the Copsa Mica water supply network is not used for drinking;

- the waste water in the city is cleaned in a station that is neither modern nor performant;

- public green areas in the city are numerous and have a neat look.

\section{Experimental part}

The soil quality survey in Copsa Mica consisted of sampling soil from an experimental field with an extended spatial distribution throughout Copsa Mica and 


\section{INTERNATIONAL SYMPOSIUM "THE ENVIRONMENT AND THE INDUSTRY", SIMI 2017, PROCEEDINGS BOOK}

beyond its limits to a distance of about $6 \mathrm{~km}$. A total of 20 soil samples were taken from depths of $0-10 \mathrm{~cm}$ and $30-40 \mathrm{~cm}$, resulting in a total of 40 soil samples. Handoperated soil sampling equipment produced by the Eijkelkamp company was used. The GPS tracking equipment used is a Garmin portable GPS receiver, the GPSmap 60CSx. The location distribution of the sampling points is shown in Fig. 2.

For each soil sample, the following quality indicators: $\mathrm{pH}$, humus, sulphates, phenols and heavy metals ( $\mathrm{Pb}$, total $\mathrm{Cr}, \mathrm{Cu}, \mathrm{Zn}, \mathrm{Fe}, \mathrm{Cd}, \mathrm{Mn}, \mathrm{Ni}, \mathrm{As})$.

The investigation of the groundwater quality in Copsa Mica consisted in the sampling activities according to of the distribution of fountains throughout the city of Copsa Mica and 2 distribution points (named "Cismea" 1 and 2). A total of 9 groundwater samples were taken, with the reference that for points F7 and F8 the underground water is captured, stored and pumped into two distribution points, locally identified as "Cismea".

For each water sample, the following quality indicators: $\mathrm{pH}$, nitrates, conductivity, sulfates, phenols, oxidation and heavy metals (Total Chromium, As, Ni, Cu, Zn, Cd, $\mathrm{Fe}, \mathrm{Pb}, \mathrm{Mn}, \mathrm{Ni}$ ) were analyzed in the R\&D Institute for Industrial Ecology ECOIND laboratories using the standardized test methods.

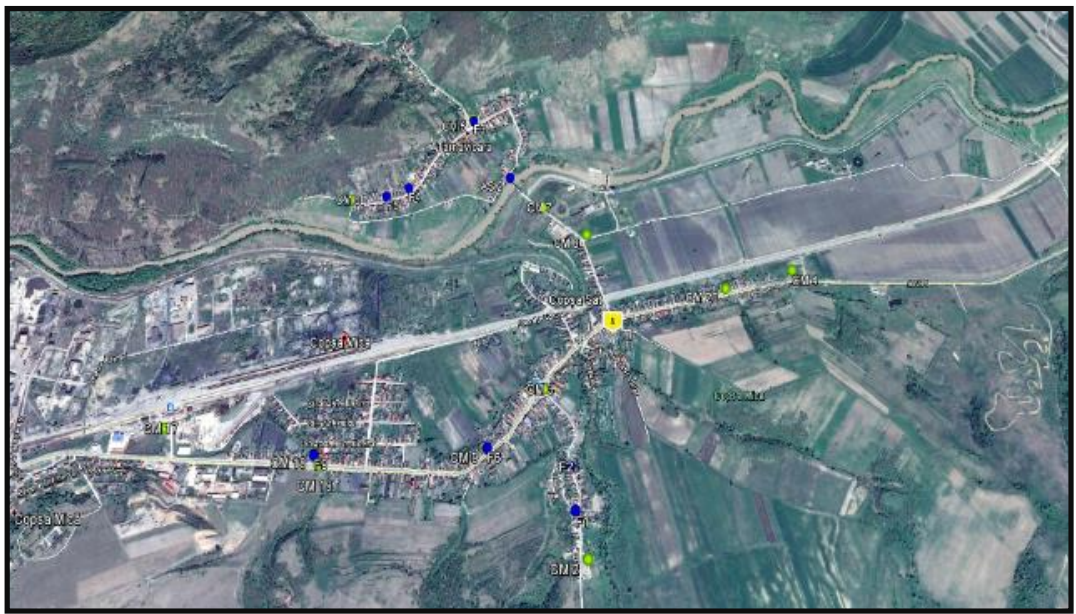

Figure 2. Distribution of sampling points (soil and water) - Copsa Mica City

\section{Results and Discussion}

Interpretation of the results of the laboratory tests made for the 40 soil samples taken from Copsa Mica, Sibiu county was done by comparison to the reference values of the Order 756 1997, respectively the reference values for chemical soil traces in soil for sensitive land use. Sensitive use is defined by Article 8 paragraph a) from the above mentioned regulation:

"Sensitive land use is represented by their use for residential and recreational areas, for agricultural purposes, as protected areas or restricted sanitary areas as well as the areas of land forecasted for such uses in the future."

The evolutions of some relevant quality indicators for the industrial activities carried out in the area of Copsa Mica are graphically presented below: 


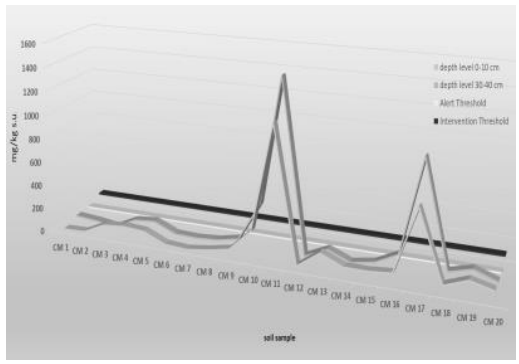

Figure 3. "Lead" content in soils samples from Copsa Mica

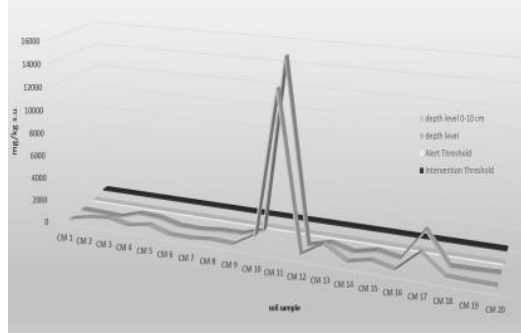

Figure 5. "Zinc" content in soils samples from Copsa Mica

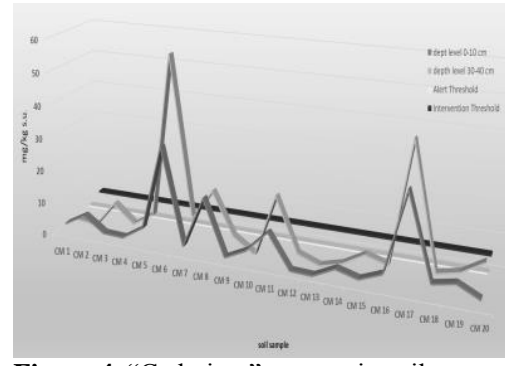

Figure 4. "Cadmium" content in soils samples from Copsa Mica

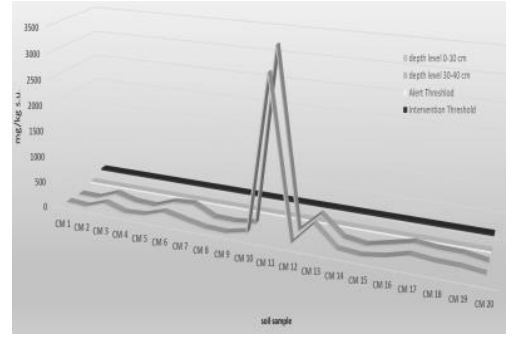

Figure 6. "Copper" content in soils samples from Copsa Mica

There are a number of negative aspects regarding the soil quality, which mainly consist in the frequent exceeding of the intervention threshold. An extremely unfavorable situation was recorded at sample "CM 11", located near DN14B, at approx. $700 \mathrm{~m}$ in the South direction of the dumps of SC Sometra SA, which is the potential source of pollution with heavy metals. A general conclusion for the soil environmental component can be formulated as follows: the soil is still affected by the residual pollution of historical nature, induced by the industrial activities carried out in the area that had a significant impact on the environment.

The groundwater quality investigations, respectively 9 groundwater samples taken from the Copsa Mica area led to results that were interpreted by comparison with the reference values of drinking water quality (Law 458 2002).

The evolutions of some relevant quality indicators for underground water in the Copsa Mica area are graphically presented in figures 7 to 10 .

This shows that the underground water supply in the analyzed area is not affected by the pollution identified in the case of soils, and under these conditions the groundwater can be considered much better in qualitative terms.

Interpretation of the results of the tests performed for the two samples of surface water taken from the area of Copsa Mica, respectively from the Visa and Tarnava Mare River, was performed using reference values according to Order 1612006.

Analyzing the obtained results, it is obvious that both water bodies analyzed correspond to a "very good" ecological status, with one exception, respectively the "Ni" quality indicator whose values impose the "good" ecological status. 


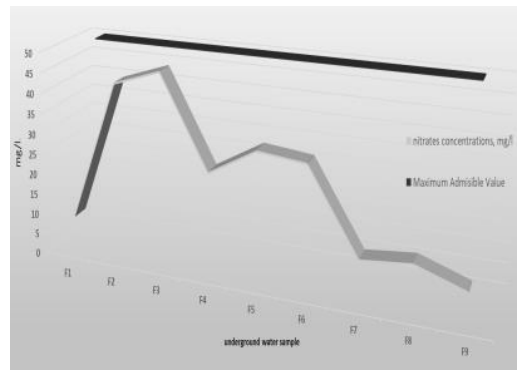

Figure 7. "Nitrates" content in underground samples from Copsa Mica

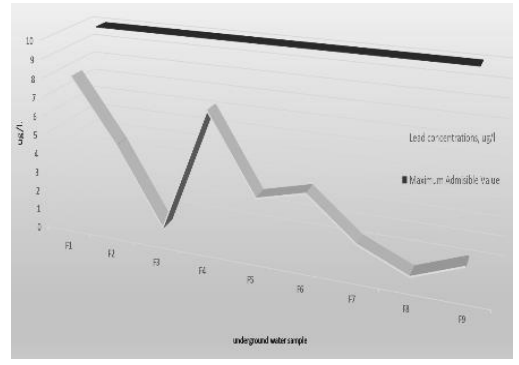

Figure 9. "Lead" content in underground water samples from Copsa Mica

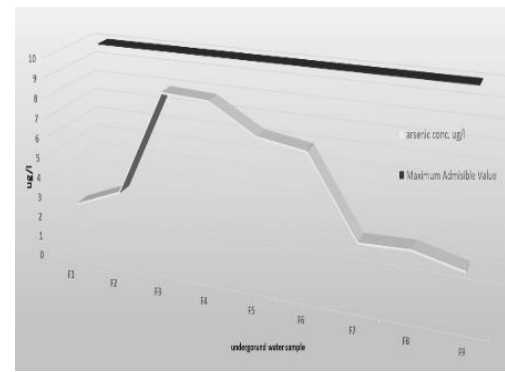

Figure 8. "Arsenic" content in underground water samples from Copsa Mica

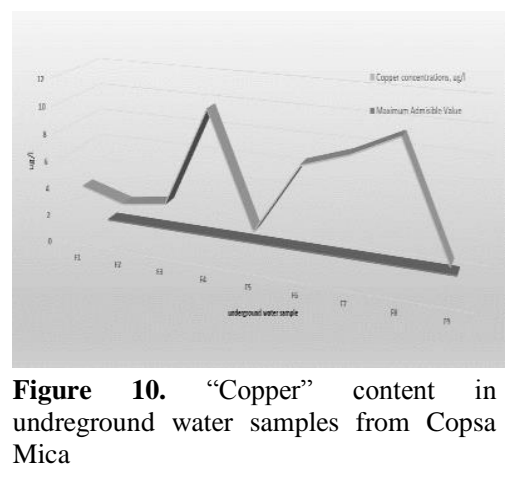

\section{Conclusions}

The project aimed to investigate the quality of the environmental components of soil and water (surface and underground water) in the Copsa Mica, a small city, known for the historical pollution recorded over several decades.

Specific soil and water quality investigations were conducted in 2016 in order to highlight the evolution and dynamics of environmental issues in a highly anthropic and polluted area (historical pollution). The experimental field will be used to highlight dynamic evolution starting from the baseline identified in 2016.

The conduct of several investigative campaigns within the proposed experimental field will create clear premises for obtaining a solid database regarding the quality of the environmental components and the evolution and dynamics of the environmental aspects for Copsa Mica, as the activities are in progress in 2017.

\section{Acknowledgements}

The project PN 16250210 is funded under the „Program Nucleu”, in period 2016-2017, conducted by the Ministry of Research and Innovation from Romania.

\section{References}

Lacatusu, R \& Lacatusu AR 2010, 'Evolution of heavy metals pollution from Copsa Mica', Scientific Papers, USAMV Bucharest, Series A, vol. LIII, pp. 85-92. 
Law 458 2002, (r1) regarding drinking water quality, Romanian's Official Monitor, Part I, no. 58, update 24 January 2012.

Muntean, E, Muntean, N \& Mihaescu, T 2010, 'Cadmium and lead soil pollution in Copsa Mica area in the relation with the food chain', Research Journal of Agricultural Science, vol. 42, no. 3, pp.731-734.

Order 756 1997, for the approval of the Regulation regarding the environmental pollution assessment, with the subsequent modifications and completions, Romanian's Official Monitor, no. 303 bis, 6 November 1997.

Order 1612006 , approving the Norms for surface water quality classification to determine the ecological status of water bodies, Romanian's Official Monitor, Part 1, no. 511, 13 June 2006.

Scradeanu, M, Iordache, V, Palcu, M \& Scradeanu, D 2016, 'Analysis of correlation between the state of groundwater and the state of terrestrial ecosystems including wetlands', International Symposium "The Environment and the Industry" SIMI 2016, National Research and Development Institute for Industrial Ecology, pp.292-300.

Stanescu, B, Kim, L, Cuciureanu, A \& Lehr, CB 2016, 'Assessment of urban soil quality in major cities in Romania. Case studies', International Symposium "The Environment and the Industry" SIMI 2016, National Research and Development Institute for Industrial Ecology, pp.112-118.

Szanto, M, Micle, V \& Prodan, CV 2011, 'Study of soil quality in Copsa Mica area with the aim of their remediation', ProEnvironment, vol. 4, pp. 251-255. 